\title{
Evaluation of Environmental Health Knowledge and Practice Among Youth Football Players in Benghazi, Libya
}

\author{
Isam Denna ${ }^{1,}{ }^{*}$, Mohamed H. ${ }^{2}$, Gawili H. ${ }^{2}$, Bumakthtra A. ${ }^{2}$, Buihjar S. ${ }^{2}$, Salem M. ${ }^{2}$, Alhassi S. ${ }^{2}$, \\ Ahmed A. ${ }^{2}$, Gasibat Q. ${ }^{3}$ \\ ${ }^{1}$ Department of Nutrition, Faculty of Public Health, University of Benghazi, Benghazi, Libya \\ ${ }^{2}$ Department of Environmental Health, Faculty of Public Health, University of Benghazi, Benghazi, Libya \\ ${ }^{3}$ Department of Rehabilitation and Sport Science, Faculty of Medicine, Sultan Zainal Abidin University, Kuala Terengganu, Malaysia
}

Email address:

isam.aldenna@uob.edu.ly (I.Denna)

${ }^{*}$ Corresponding author

\section{To cite this article:}

Isam Denna, Mohamed H., Gawili H., Bumakthtra A., Buihjar S., Salem M., Alhassi S., Ahmed A., Gasibat Q. Evaluation of Environmental Health Knowledge and Practice Among Youth Football Players in Benghazi, Libya. Rehabilitation Sciences. Vol. 3, No. 1, 2018 , pp. $23-27$. doi: $10.11648 /$ j.rs.20180301.15

Received: February 7, 2018; Accepted: February 25, 2018; Published: March 24, 2018

\begin{abstract}
Environmental health issues and practices are important in sport to reduce the risk of diseases occurrence and transmission. However, there is lack of a data about them among football players in Libya. This study aims to assess the environmental health knowledge and practices among youth football players in Benghazi, Libya. The study involves 182 participants who were involved from five youth football clubs with age means $(17 \pm 1.3 y s)$. Players filled self-prepared questionnaire, which contained two sections :environmental knowledge and practices. The collected data was analyzed using SPSS. Almost $62 \%$ of the participants had not attend any lecture about environmental health. Markedly, 58\% of players sharing their tools with others; in particular towels and water bottles. $75 \%$ of the sample were non-familiar with the hazards of sharing tools and $65 \%$ did not know about blood-born infections and their transmission mode. $81 \%$ of participants did not receive vaccinations, and 125 did not receive any acclimation programs about playing in changed temperature environment. In this study, there was a lake of knowledge about essential environmental health issues as well as poor practices regarding to sharing tools, vaccinations and acclimation practices. Hence, establishment of environmental health education programs among footballer players is of great significant.
\end{abstract}

Keywords: Environmental Health Issues, Youth, Awareness, Libyan Football Players

\section{Introduction}

Sport and exercise are considered to have long-term health benefits for participants; however, all physical activity carries risks that participants will sustain an injury or ill-health and these must be balanced against the benefits (Fuller and Vassie, 2004; Gasibat. Q et al., 2017). Football is the most popular sport worldwide for men, women and children (Kunz, 2007). Environment in which the football players practice, compete and sometimes receive therapy for injuries in emergency cases, play an essential role in transmission of infectious pathogen among players (Turbeville et al., 2006). Furthermore, football players are exposed to several risk factors in playing environment; which include; infections, thermal stressors (i.e. hot, cold, humid condition, etc). In this context, hot playing environment causes an increase in the core body players temperature and production of metabolic heat, which subsequently will reduce the exercise capacity and performance (Taylor and Rollo, 2014).

Likewise, altitude have a significant effect on performance. It appears to have their greatest impact very early in the altitude exposure, and their physiological/neurosensory consequences are ameliorated by acclimatization. Playing in low altitude environment leads to reduction of oxygen, which decreases oxygen delivery to the skeletal muscle, and inhibits the chance of recovery and take while to return to sprint activities. Moreover, altitude acclimatization is dependent on the altitude that match play will be at nutritional preparation may include dietary nitrates as well as iron (Taylor and Rollo, 2014; Gasibat. Q et al., 2017). 
Regarding risk factors, most of infectious diseases outbreak happened in competitive sports such as football games (James et al., 2010). Collins and colleagues (2012) found that the most common pathogen was MethicillinResistant Staphylococcus Aureus (MARSA) and tinea (Trichophytosis). The authors $71 \%$ of these infection site included skin and soft tissue. In other study, Glasset al. (2007) reported that bacteria, fungi and yeasts can be transmitted by athletic mouth guards which are worn byfootballer players.

Glass et al. (2011) Demonstrated that the most common gram- positive cocci and bacilli species were Staphylococcus spp, and Brevibacterium spp. Respectively. However, the mostcommon mold species were Cochliobolus spp, and Penicillium chrysogenum., WhileCandida parapsilosis was the most common species of yeast. Moreover, they Indicated that recontamination of these species through these guards occur rapidly.

The common sources of infection in the environment involve drinking cups and water bottles, soap and towels (Nguyen et al., 2005). Lockerrooms, fencing equipment, athletic equipment. On the other hand, the most common transmission mode of these infections is direct contact such as skin to skin contact, and it can be transmitted through blood borne and respiratory route or it can be common sources exposure such as transmitted though the athletic equipment (Tuberville et al., 2006). Additionally, International sporting gives opportunity to transmit indigenous measles among athletes as reported by Centers for Disease Control (CDC) (CDC, 1992) So that, the recommendations ofAmerican conference of governmental industrial hygienists (ACGIH) and CDC (1983) include provide the athletes immunization against rubella, measles and mumps.

There is relationship between immunity system, intense and heavy training. In this context, heavy exercise could lead to decrease neutrophil function as well as suppression to the function of immune system for 3 to 12 hours, and this case known as open window which could elevate the risk of upper respiratory tract infection (David et al., 1997). In fact, it does result from having low levels of salivary IgA secretion. Similarly, the overtraining is correlated with recurrent athletes' infection because of the same reason (Papa Costa\& Gleeson, 2013).

Papa Costa\& Gleeson (2013) indicated that intensified training can result in immunity depression, as result of alteration in cytokine response to the stimulation of antigen and exercise. Additionally, it induces the muscle damage as result effect of intensive training on generating reactive oxygen species (ROS) in leukocytes, this will cause reduce in physical performance and fatigue of the muscles. (Nielsen, 2013)

Important of study: Reduce the incidence of infections and thereby diseases transmission occurrence to ensure safe performance in the sports.

Aim of study: To assess environmental health knowledge and practices among youth footballer players in 5 sports clubs in Benghazi, Libya.

\section{Materials and Methods}

\subsection{Ethical Considerations}

Ethical approval for the study was obtained from 5 sports clubs after directing a permission letter from the faculty of public health with a written agreement from sample participants.

\subsection{Study Area}

The study was conducted on youth football players in five different clubs at Benghazi Libya. These are: Al-Ahly Benghazi, Al-Naser, Al-Sad, Al-Njoum and North Benghazi club.

\subsection{Study Design and Protocol}

A cross-sectional study was conducted over two months on (September - October) 2016. The target population was youth football players, and the sample included 182 youth players who are currently playing in five clubs in Benghazi city with age mean $(17 \pm 1.3)$ years. The data was collected by using a self-prepared questionnaire. The questionnaire involved two sections: evaluation of environmental knowledge (e.g. Have you attended any lecture about environmental health before, are you aware about the problems can happen due to sharing tools) and evaluation of environmental practices (e.g. Does the club provide any acclimation programs through different climates, in case of playing in high temperature climate does your water intake increases?) among sample population.

\subsection{Statistical Analysis}

Data generated from questionnaires was analyzed using statistical package for the social sciences (SPSS) version 22. Simple statistical analysis software was used to express the results and comparisons between the stratified samples.

Results

A. Environmental health knowledge:

The statistical analysis demonstrated that $62 \%$ of the sample had not attend any educational lecture about environmental health (Figure 1). The most common cause for non -attendance is that the club did not provide this type of lecture $(62 \%), 14 \%$ for non-interested, $3 \%$ of the sample did not have time, and about $21 \%$ of the participants had other reasons (Figure 2).

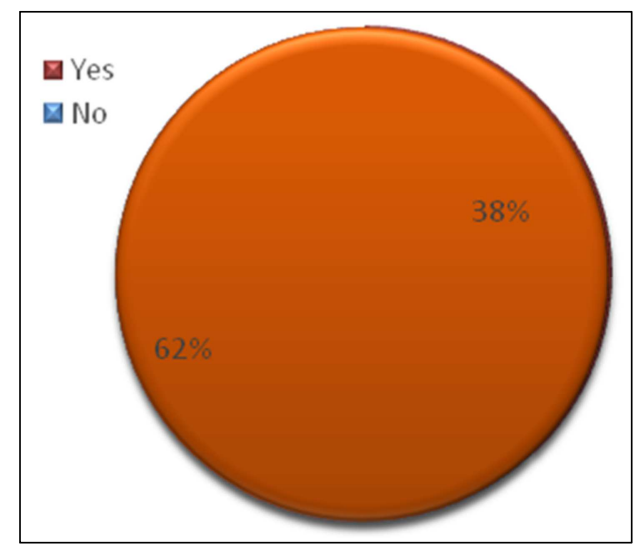

Figure 1. Attendance to education lectures about environmental health. 


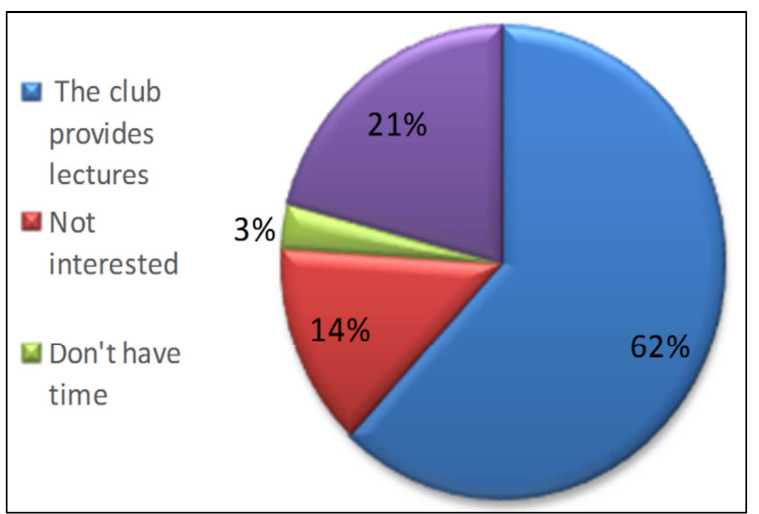

Figure 2. Causes of non-attendance to education lectures about environmental health.

Furthermore, $75 \%$ of the players had not any knowledge regarding to the problems that can be happened due to sharing their tools in the clubs (Figure 3).

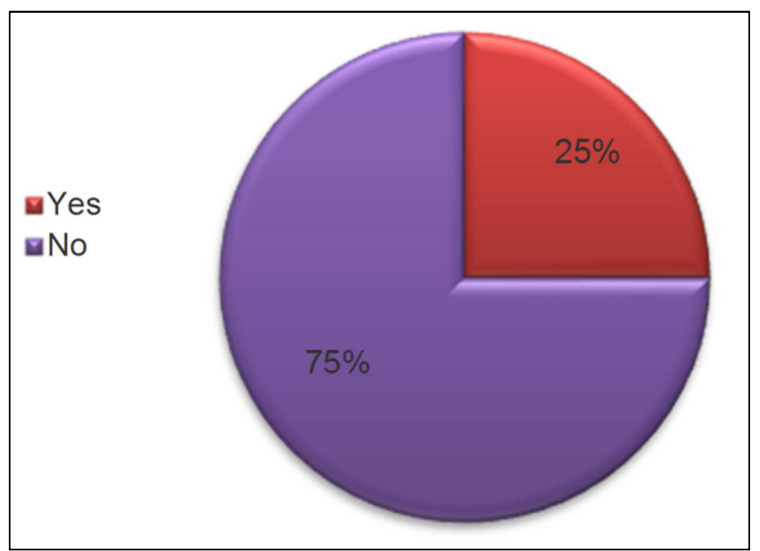

Figure 3. Knowledge about the problems which can happen due to sharing tools.

On the other hand, the current study shows that just $35 \%$ of the sample know about blood-borne diseases and their ways of transmission (Figure 4). Moreover, the results showed that 54\% of sample do not know about the transmission of diseases through the food and drink (Figure 5).

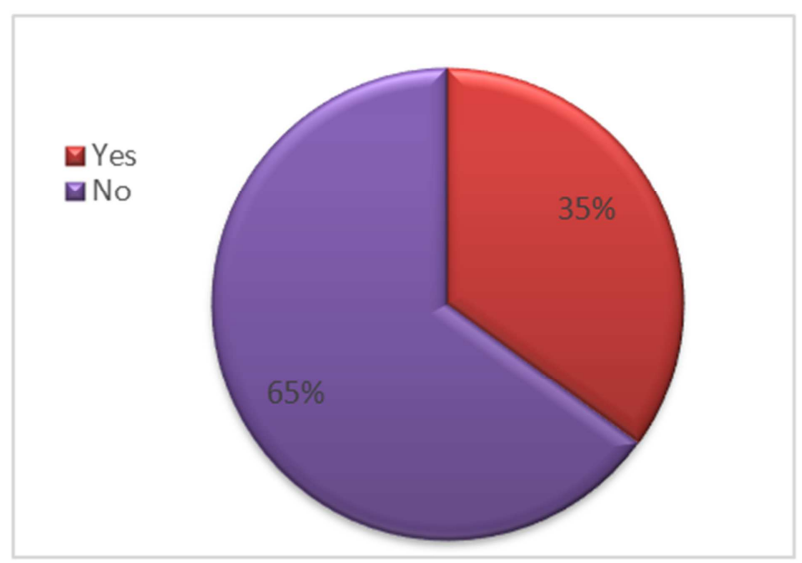

Figure 4. Knowledge about blood borne diseases.

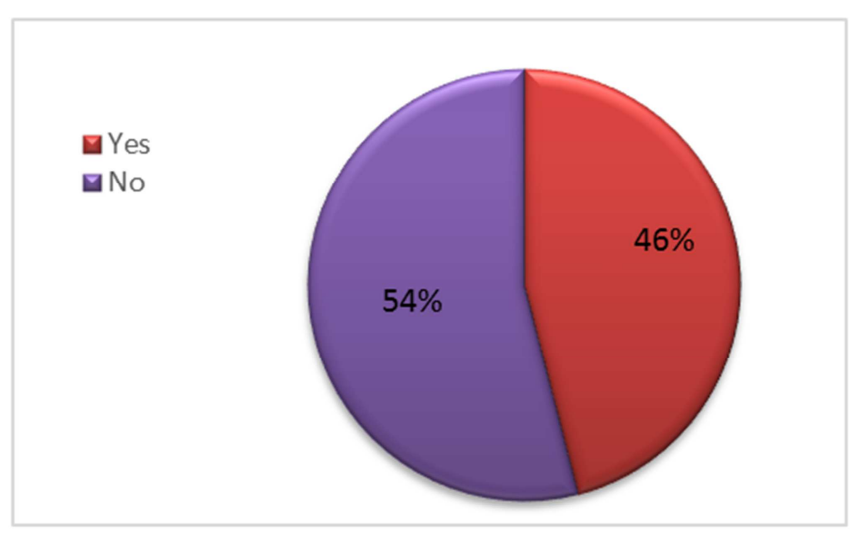

Figure 5. Knowledge about diseases which can be their ways of transmission transmitted by food and drink.

B. Environmental health practices:

Regarding sharing the tools, $58 \%$ of the players sharing their tools with other, while $42 \%$ of the participant did not share. In more specific, the results showed that $49 \%$ of the participants share their clothes, water and drink bottles, while $1 \%$ share their towels and hair combs (Figure 6).

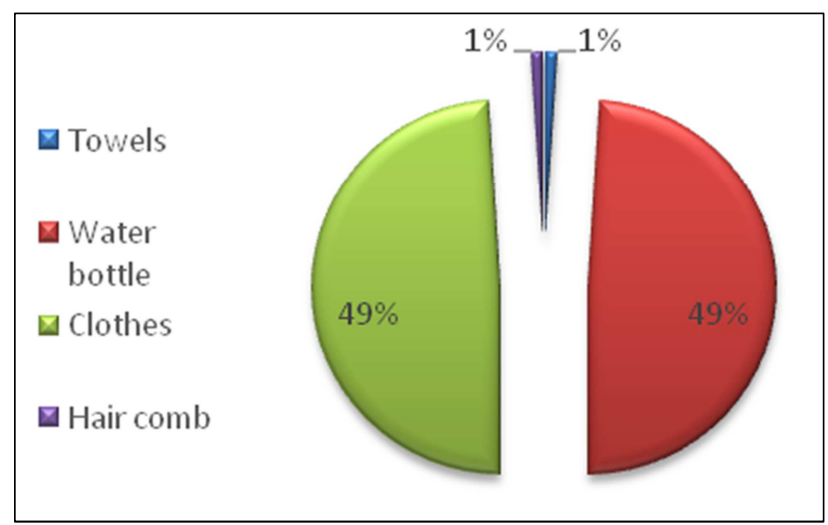

Figure 6. Types of shared tools.

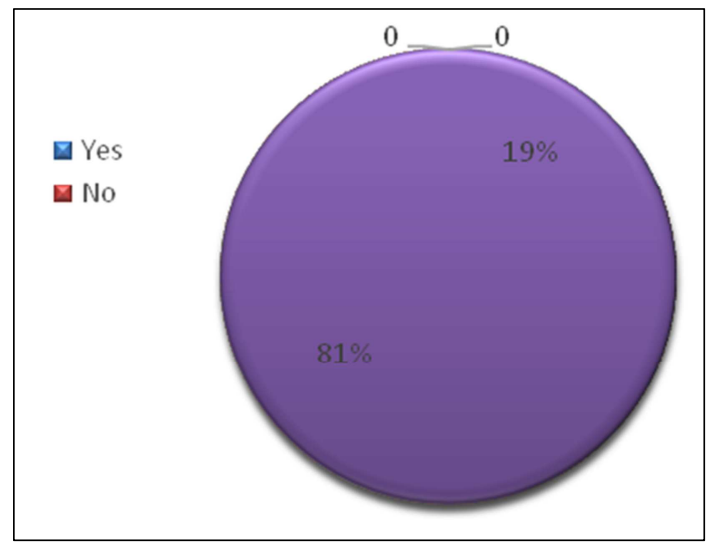

Figure 7. Vaccinations provided by the club.

Regarding to acclimatization program, the highest percentage of the sample had not admitted any acclimation program provided by the clubs, which was $69 \%$. On the other hand, about $31 \%$ of the participants admitted to this program. In more detail, participants who admitted acclimation 
program by the club, $77 \%$ of them receive comprehensive program for acclimation in high playground and high and low temperature environment (Figure 8). Only 18\% have received program about playing in high temperature environment, $3 \%$ and $2 \%$ for receiving program about adapting in low temperature and high playground environment, respectively.

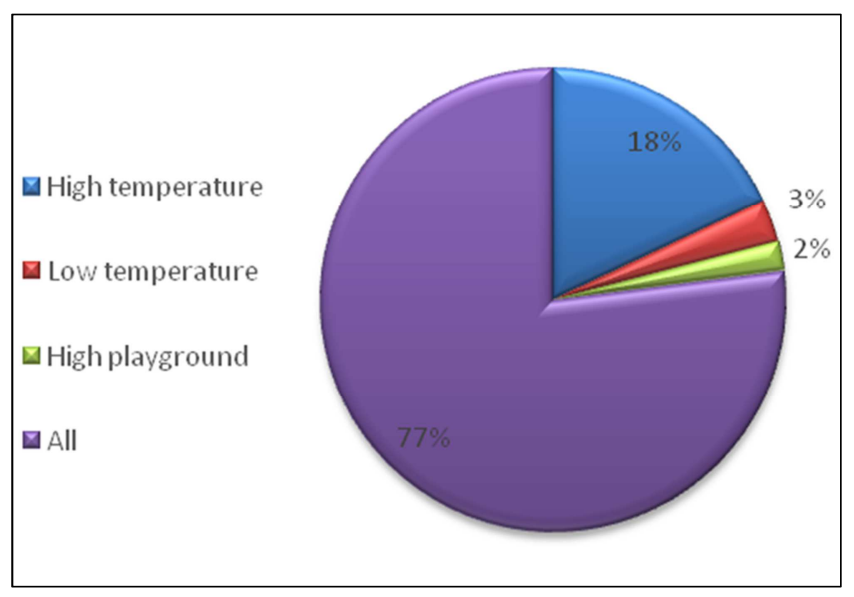

Figure 8. Acclimation programs provided by the club.

\section{Discussion}

A. Environmental health knowledge

More than half of the participants $(62 \%)$ did not attend to any educational lecture about environmental health issues before. This result indicates that there is a lack of awareness and knowledge about environmental health issues which is an important matter. In this context, there is a deficiency in the knowledge about the modes and routes of diseases transmission and thereby disease occurrence. Hence, the clubs must provide regular lectures to aware the players about the important issues of environmental health to decrease the risk of disease transmission and their occurrence.

This study showed that $75 \%$ were not familiar with the problems that occur due to sharing personal tools among the players, for example water bottle or towel. In fact, these habits are considered as the main causes of the spread of infections (Kathryn A et al, 2009).

Our results showed that $65 \%$ of the participants were not aware with the ways that diseases transmitted through blood. On the other hand, $54 \%$ of the whole sample do not know about the diseases transmitted by food, drink and sharing because of the lack of awareness that causes spread of the infection and diseases among players. Coaches and footballer players should be educated about how to prevent the spread of diseases to participate in sport safely (Kathryn A et al, 2009). This is because of the occurrence of diseases among sports players would decrease the performance.

In this study, $98 \%$ of the sample members were suffered from skin diseases. In fact, the clubs should provide the necessary educational lectures to reduce the infections among players and enhance the awareness about how to deal with different types of diseases. Furthermore, there is necessity to build educational programs to avoid spread of infection. Moreover, it is a great importance to build infection and control measurements like do not share uniforms, socks or shoes, put strict personal hygiene rules (Kathryn A et al, 2009).

Less than half of the sample members (29\%) did not have a medical record. All sports clubs must have a database with all information on their player members, so that each player have medical record in relation with health status and medical history.

B. Environmental health practices

$81 \%$ of participants do not have before any preventive vaccinations. Moreover, $42 \%$ reported that the club medical teams do not perform regular periodic examination. In fact, it is important to provide each player with the necessary vaccinations against certain diseases to ensure their safety from getting any illness, especially in the case of travel.

More than half of sample members (58\%) are sharing personal tools, which leads to the spread of infections such as skin infections and hepatitis A (Kathryn A et al, 2009). In this context, $49 \%$ do share a bottle of water or drink, their clothes. Just $1 \%$ of the participants do share special towels and hair comb with other players which could cause the spread of some microbes such as fungi (Kathryn A et al, 2009).

Majority of sample $(97 \%)$ has admitted that causes of skin diseases among players is the lack of cleanliness of the facility such as bathrooms or lockers room. This is very important issue related to environmental health and poor hygiene in the club which subsequently leads to occurrence of infections that spread and transmitted through body fluids.

$69 \%$ of the participants showed that the club did not provide them with any of acclimation programs for heat or cold environment. However, most important criteria in the clubs to provide such a kind of programs which is different climate to avoid injuries and illness such as heat stroke and frostbite. $77 \%$ of members who admitted acclimation program by the club, receive comprehensive program for acclimation in high playground and high and low temperature environment. Only $18 \%$ received program about playing in high temperature environment, $3 \%$ and $2 \%$ for receiving program about adapting in low temperature and high playground environment, respectively.

\section{Conclusion}

The results of present study showed that there was inadequate knowledge level regarding environmental health and practices. The lowest levels were observed regarding sharing tools, blood-borne diseases, diseases transmitted through food and drink, vaccinations and acclimation practices. Hence, establishment of education programs among footballer players would be of great significant. Moreover, there is a great need to properly allocate the environmental health professionals at sports clubs. 


\section{References}

[1] Adams BB. Tinea corporis gladiatorum: a cross sectional study. J Am AcadDermatol. 2000; 43:1039-1041.

[2] Centers for Disease Control (CDC, 1992. Measles at international gymnastics competition--Indiana, 1991. MMWR. Morbidity and mortality weekly report, 41 (7), p. 109.

[3] Collins, C. J. and O'connell, B., 2012. Infectious disease outbreaks in competitive sports, 2005-2010. Journal of athletic training, 47 (5), pp. 516-518.

[4] Fuller CW, Vassie LH. Health and Safety Management: Principles and Best Practice. Harlow: FT Prentice Hall 2004.

[5] Fuller CW, Ward CJ. An empirical approach for defining acceptable levels of risk: a case study in team sports. InjPrev 2008; 14:256-61.

[6] Glass, R. T., Conrad, R. S., Köhler, G. A., Warren, A. J. and Bullard, J. W., 2011. Microbiota found in protective athletic mouthguards. Sports health, 3 (3), pp. 244-248.

[7] Glass, R. T., Wood, C. R., Bullard, J. W. and Conrad, R. S., 2007. Possible disease transmission by contaminated mouthguards in two young football players. General dentistry, $55(5)$, p. 436.

[8] Glass, R. T., Conrad, R. S., Wood, C. R., Warren, A. J., Kohler, G. A., Bullard, J. W., Benson, G. and Gulden, J. M., 2009. Protective athletic mouthguards: do they cause harm? Sports health, 1 (5), pp. 411-415.

[9] Kathryn A, Terence B, Roald B et al (eds) (2009) (second edition). "Football Medicine Manual". Fédération Internationale de Football Association (FIFA).

[10] Kunz M. Big count: 265 million playing football. FIFA Magazine 2007:10-15.

[11] Nielsen, H. G., 2013. Exercise and immunity. In Current Issues in Sports and Exercise Medicine. In Tech.

[12] Nieman, D. C., 1997. Immune response to heavy exertion. Journal of applied physiology, 82 (5), pp. 1385-1394.

[13] Nguyen, D. M., Mascola, L. and Brancoft, E., 2005. Recurring methicillin-resistant Staphylococcus aureus infections in a football team. Emerging infectious diseases, 11 (4), pp. 526532 .

[14] Papacosta, E. and Gleeson, M., 2013. Effects of intensified training and taper on immune function. RevistaBrasileira de EducaçãoFísica e Esporte, 27 (1), pp. 159-176.

[15] Taylor, L. and Rollo, I., 2014. Impact of altitude and heat on football performance. Sports Science Exchange, 27 (131), pp. $1-9$.

[16] Turbeville, S. D., Cowan, L. D. and Greenfield, R. A., 2006. Infectious disease outbreaks in competitive sports. The American journal of sports medicine, 34 (11), pp. 1860-1865.

[17] Gasibat Q, Dermish HM, Alhmali RR, Denna I (2017) Evidence of Significant Results Showing Staying Active is Advisable for Non-Specific Low Back Pain Patients: A systematic Review. Int Phys Med Rehab J 1 (6): 00033. DOI: 10.15406/ipmrj.2017.01.00033.

[18] Gasibat Q., Simbak N., Aniza A. A., \& Musa R. M. (2017). A comparative efficacy between strength and Stabilisation training programmes in the Improvement of trunk and hip muscles Activations of healthy females subject: An implication for the rehabilitation Practitioners. International Journal of Life \& Pharma Research, 7 (4), 30-38. In press. 